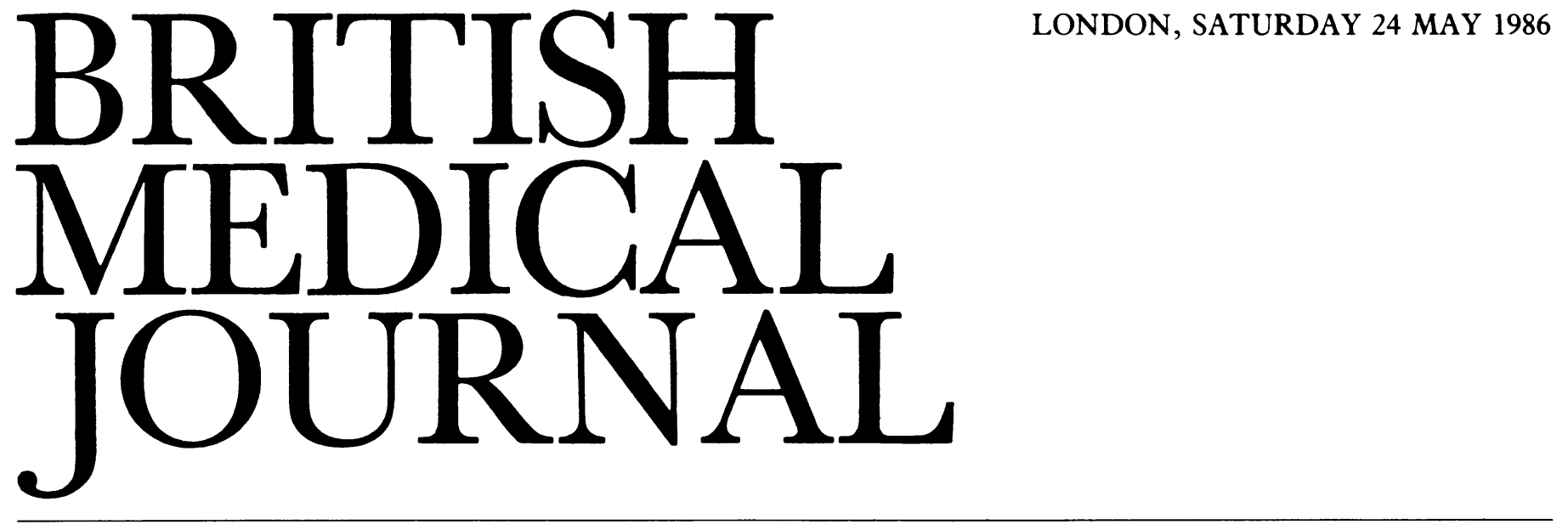

\title{
Drugs in developing countries: inching towards rational policies
}

Many people in developing countries still have no access to basic lifesaving drugs. Others are deluged with thousands of dubious preparations under a bewildering choice of brand names. Polypharmacy is rampant, and inappropriate prescriptions, false packaging, and substandard and even fake drugs are common. Nor is it unusual for people to buy their drugs over the counter, like peppermints, from local shopkeepers who do not let their ignorance of pharmaceuticals interfere with a lively trade in extraordinary combinations of tonics, appetite stimulants, vitamins, and hormones. So given that all this could have been written 10-15 years ago, what is new? The quick answer is nothing dramatic, but there are encouraging signs that the use and misuse of drugs in many developing countries, and the urgent need of these countries to adopt rational drug policies, are receiving more attention than ever before.

This does not, of course, necessarily mean that the status quo has changed. Indeed, according to a recent report from Health Action International (launched on 13 May at the 39th World Health Assembly in Geneva), "most of the tens of thousands of drugs on the world market are either unsafe, ineffective, unnecessary, or a waste of money." Self styled as a network of some 50 non-governmental organisations campaigning for rational drug use, Health Action International is not without its bias. Nevertheless, its findings, particularly with respect to the developing countries, are disquieting.

Among the 24 different types of drugs investigated antidiarrhoeal preparations are one of the major groups singled out and accused of being ineffective, occasionally harmful, and grossly overused. The view that they are overused is supported by the figure for the sales of these preparations in the 12 months $1983-4$ : an estimated $\$ 438 \mathrm{~m}$. Health Action International implies that vast amounts of these drugs are being used in developing countries to treat young children with diarrhoea, a condition that is responsible for up to 5 million deaths a year. Oral rehydration salts are now widely accepted as the treatment of choice for most of these cases, and if the cost of supplying sufficient salts to prevent most of the deaths is of the order suggested- $\$ 200$ $300 \mathrm{~m}$ a year ${ }^{2}$ - there is some justification for Health Action International's belief that the scale of the possible wastage of money on inappropriate medication is depressing.

No less depressing are Health Action International's findings on the widespread and indiscriminate use of anti- biotics for trivial diseases and for disorders that do not respond to antibiotics. Although this is a global problem, an illustration of their misuse in developing countries touches on diarrhoea again; $65 \%$ of the antidiarrhoeal preparations listed in eight prescribing guides in Asia, the Middle East, Africa, the Caribbean, and South America in 1985 contained an antibiotic. Thus the World Health Organisation's advice that "antimicrobial drugs are not indicated for the routine treatment of acute diarrhoea" and that their indiscriminate use "should be discouraged, not only because antibiotics have no therapeutic value, but because they are needlessly expensive and may be harmful" seems to have fallen on unreceptive ears. Multiple drug resistance is undeniably going to become more widespread and difficult to surmount in the future. Additional findings suggest that four fifths of the 546 products on the market for coughs and colds in Indonesia, India, the Middle East, Africa, and the Caribbean are irrational combinations and that over three quarters of the 888 vitamin preparations on the market in these areas are ineffective or used irrationally at incorrect dosages, at needless expense to those concerned.

So where are the encouraging signs that progress towards a rational approach to medicines in developing countries is being made? Most such signs relate to the increasing number of forums where the topic is being aired. Last week the WHO assembly discussed the strategy drawn up at the WHO conference of experts on the rational use of drugs, which took place in Nairobi last November, and made three major proposals. Firstly, governments should adopt national drug policies based on the WHO's essential drug concept and use the skill of the WHO in drawing up these policies. Secondly, they should set up effective national regulatory authorities, and developed countries should help them. Thirdly, efforts should be made to ensure that drug promotion is ethical and that the education of health workers is improved. In addition, information on the drugs must be adequate and accurate and storage and distribution of drugs should be improved.

Another debate took place at the London School of Hygiene and Tropical Medicine on 29 April. Although it tended towards the usual pattern: a battle between the white knight (the WHO and its essential drug list together with other supporters of limited lists) and the black knight (the conveniently if unfairly homogenised pharmaceutical industries), some up to date information was presented. 
Eighty countries have adopted the WHO's list of 200 or so essential drugs. Of these, those with the longest experience with a limited list (Papua New Guinea, Mozambique, Sri Lanka, Kenya, and Tanzania) are beginning to evaluate the medical, economic, and political implications of this policy. In collaboration with Unicef and other organisations the WHO has succeeded in decreasing the prices of drugs to the extent that all those needed for primary health care should cost no more than about $35 \mathrm{p}$ a head a year. Speaking on behalf of the WHO, E Lauridsen said that countries that paid over the odds for their drugs-sometimes 10 times over-did so not through ignorance of the correct sources of cheap, high quality drugs but for political motives of their own.

Two further meetings are scheduled for next month. Firstly, the European parliament is going to debate the draft report prepared by Mrs M Banotti on the export of drugs from the European Community to the Third World. The key recommendation is that drugs banned, withdrawn, severely restricted, or not licensed for sale within the EEC should not be exported to developing countries-unless the health authorities have requested it in the full knowledge of the controls that have been applied in Europe. This is a welcome initiative for it could do a lot to eliminate the double standards that are being applied with respect to safety. Secondly, 18 motions have been put forward for discussion at the next annual representative meeting of the British Medical Association (23-26 June) on the problems of supplying developing countries with essential drugs, ways to persuade the pharmaceutical industry not only to respond to this need but also to devote more money towards the research and development of drugs to treat tropical diseases, and stopping the supply of irrational and inessential drugs.

In response to this mounting pressure the pharmaceutical industry has retaliated. The Association of the British Pharmaceutical Industry has described Health Action International's findings as alarmist, re-emphasising that the association supports the establishment of effective national medicines policies and regulatory bodies and the extension of the WHO's certification scheme to ensure the quality and availability of full information about medicines world wide. What the industry is clearly not prepared to accept, however - and rightly - is the role of scapegoat for the Third World's health problems. Its arguments are well rehearsed: developing countries need to increase their literacy rates, establish systems of political and social order, improve transport and communication systems, provide clean water supplies and effective sanitation, improve local agricultural economies, and build up effective primary and secondary health care services. ${ }^{3}$ Improving the health care infrastructure by these means is, it argues, more important than imposing rigid limited lists.

No one would dispute that these measures are vital, or that the experience of those developing countries with limited lists should be evaluated very carefully, for there are lessons to be learnt. In Bangladesh, for example, where there has been a limited list for nearly four years, the policy has been successful but it has created some difficulties. ${ }^{45}$ Nevertheless, surely the industry should shoulder much of the blame for the current inappropriate and excessive use of medicines in developing countries. And it must produce more convincing arguments to support its thesis that the voluntary code of practice of the International Federation of Pharmaceutical Manufacturers Association (designed to protect consumers against unethical drug promotion) is working. It is encouraging to see that the industry is showing concern, but it must show its critics that this is more than skin deep.

Assistant editor, $B M \mathcal{F}$

TESSA RICHARDs

1 Chetlev A, Gilbert D. Problem drugs. The Hague: Health Action International, 1986.

Rhode JE. Selective primary health care: strategies for control of disease in the developing world XV. Acute diarrhoea. Rev Infect Dis 1984;6:840-54.

Taylor D. Pharmaceutical briefing. Development, health and the need for pharmaceuticals. London: Association of the British Pharmaceutical Industry, 1986

Islam SMD. Drug policy in the Third World. Lancet 1985; ii:46-7.

5 Ahmed M. Drug policy in the Third World. Lancet 1985; ii:47.

\section{Progress towards a new pertussis vaccine}

In 1975 the pertussis vaccine used in Japan was withdrawn $\vec{\circ}$ after the sudden deaths of two recently vaccinated infants. The vaccination programme was later reinstated, but public $\stackrel{\vec{D}}{\vec{D}}$ confidence was not restored, and the poor uptake led to a 3 swift resurgence of whooping cough. ${ }^{1}$ In Britain, too, i pertussis epidemics returned rapidly when acceptance fell in $\stackrel{0}{N}$ the mid-1970s after adverse publicity about the safety of the of vaccine. The need for routine pertussis immunisation is now no longer questioned in Britain and interest is currently $\vec{\omega}$ focused on the development of a purified vaccine containing $\underset{\forall}{ \pm}$ identifiable protective antigens.

Whole cell vaccine consists of a suspension of killed $N$ Bordetella pertussis organisms. It is, therefore, a mixture of antigens, some of which-while essential for protectionmay also produce reactions. The aim of current research is to $\overrightarrow{0}$ identify and purify the protective antigens from the whole $\stackrel{\infty}{\infty}$ cell and inactivate those which are toxic-and so to assemble a component vaccine which gives good protection with minimal reactogenicity. The main toxic component of the organism is thought to be lymphocytosis promoting factor. When injected into animals this factor causes lymphocytosis, $\stackrel{\varnothing}{\stackrel{\circ}{2}}$ hypoglycaemia, histamine sensitisation, and other effects. $\vec{P}$ There is general agreement that lymphocytosis promoting 3 factor, suitably treated to destroy its toxic activity while $\bar{F}$ retaining its immunogenicity, should be included in a vaccine to protect against the toxic effects of the infection. ${ }^{2} \mathrm{~A}$ second component thought to be important for protection is filamentous haemagglutinin, a surface antigen which prob- $\dot{0}$ ably plays a part in the initial colonisation phase of the infection and appears to be non-toxic. ${ }^{23}$ Opinion about the $ᄋ$ importance of serotype specific agglutinogens is divided despite both laboratory and epidemiological evidence sug- 9 gesting that these antigens are concerned in protection. ${ }^{45} \mathrm{~N}$ Several other components of $B$ pertussis have been identified, $\vec{D}$ and some are known to induce antibodies in recipients of whole cell vaccine, ${ }^{6}$ but their importance in protection is $\tilde{\mathrm{O}}$ uncertain. There is agreement, however, that a component $\underset{\mathrm{N}}{\mathrm{N}}$ vaccine should contain little or no lipopolysaccharide antigen, ₹ an endotoxin present not only in $B$ pertussis but in other Gram negative bacteria. ${ }^{2}$

Component vaccines containing variable amounts of filamentous haemagglutinin and inactivated lymphocytosis promoting factor (but with some degree of contamination with other antigens) were introduced in Japan in 1981 for routine $\mathbb{\mathbb { D }}$ use in 2 year olds. ${ }^{1}$ Laboratory tests showed the vaccines to be less toxic than the whole cell preparations, and they are reported to have produced fewer feverish and local reactions in children. ${ }^{1}$ A clinical protection trial of two Japanese component preparations has started in Sweden, where 